\title{
ОШИБКИ СУДЕБНОЙ ЭКСПЕРТИЗЫ: КЛАССИФИКАЦИЯ, ВЫЯВЛЕНИЕ, ПРЕДУПРЕЖДЕНИЕ
}

\author{
Россинская E.P.
}

Аннотация. Настоящчая статья посвящчена анализу типов и причин возникновения ошибок, допускаемых при производстве различных видов судебных экспертиз. В статье приведена современная классификация экспертных ошибок. Приводится сопоставление разработанных в судебной экспертологии подходов к изучению экспертных ошибок. Рассмотрены и проиллюстрированы на конкретных примерах основные прочессуальные, гносеологические (логические и фактические) и деятельностные (операциональные) экспертные ошибки. Проанализированы пути выявления и предотвращения экспертных ошибок в судопроизводстве по уголовным и гражданским делам, в разбирательстве по делам об административных правонарушениях. В ходе данного исследования для анализа и группировки различных типов экспертных ошибок применялся метод классификации. Причина ошибочности экспертного заключения может быть не только в допущенных экспертом ошибках. Экспертное исследование может быть выполнено безупречно, сделанные выводы полностью соответствуют полученным результатам. Но если исходные данные были ошибочными или исследуемые объекты не имели отношения к делу, были фальсифицированы, то и заключение эксперта в аспекте установления истины по делу окажется ошибочным. Однако в этом случае нельзя говорить об экспертной ошибке, поскольку причиной ошибочного заключения является ошибка субъекта, назначившего экспертизу, либо его умышленно неправильные действия, правонарушения.

Ключевые слова: ошибки судебных экспертиз, процессуальные, экспертные ошибки, фактические экспертные ошибки, методические экспертные ошибки, заключение эксперта, классификация, выявление, предупреждение, очибочное заключение.

"Доказательственное значение заключения эксперта зависит от его истинности, внутренней непротиворечивости, точности и достоверности всех действий, оченок и выводов эксперта в ходе и по результатам процесса экспертного исследования».

Белкин Р. С. Курс криминалистики. 3-е издание дополненное.-M., 2001, с. 470.

Эксперт проводит исследования объективно, на строго научной и практической основе, в пределах соответствующей специальности, всесторонне и в полном объеме 1 . Однако, как лю-

\footnotetext{
${ }^{1}$ Ст. 8 Федерального закона от 31 мая 2001 г. № 31-Ф3
}

бой человек, судебный эксперт может допускать ошибки. В то же время, ошибки, допущенные экспертом в процессе производства экспертизы

«О государственной судебно-экспертной деятельности в Российской Федерации» (далее по тексту ФЗ ГСЭД). 
и подготовки заключения по ее результатам, могут сделать это доказательство ничтожным ${ }^{1}$. Объективизация процесса доказывания требует предупреждения и своевременного распознавания экспертных ошибок, а, в конечном счете,искоренения причин, их порождающих.

Экспертные ошибки следует отличать от заведомой ложности заключения, поскольку за дачу заведомо ложного заключения эксперта ст. 307 УК РФ предусмотрена уголовная ответственность. Однако в литературе нередко отсутствует четкое разграничение ошибочного заключения вследствие добросовестного заблуждения эксперта и заведомо ложного экспертного заключения. Так авторы Комментария к Уголовному кодексу Российской Федерации под. ред. А. И. Чучаева ${ }^{2}$, комментируя ст. 307, указывают, что «заключение эксперта является ложным, если оно содержит искажение фактов, неверную оценку либо выводы, не основанные на материалах уголовного, гражданского или арбитражного дела. Это может, например, относиться к оценке вреда, причиненного здоровью (вместо средней тяжести указывается тяжкий или наоборот) ...» Совершенно непонятно, почему заключение эксперта, содержащее неверную оценку фактов, сразу трактуется как заведомо ложное, и в расчет не принимается возможность экспертной ошибки в силу добросовестного заблуждения. Еще более странным является требование основывать заключение эксперта на других материалах дела, с которыми, во-первых, может вообще не быть никакой связи, например, при производстве автотехнической экспертизы по установлению механизма дорожно-транспортного происшествия, когда результаты экспертизы противоречат показаниям фигурантов по делу. Показания могут быть как заведомо ложными, так и результатом добросовестного заблуждения. Следует напомнить, что ни одно доказательство не имеет заранее установленной силы.

Во-вторых, именно такие комментарии, когда эксперту предлагается решать вопросы, связанные с квалификацией деяния «оценке вреда, причиненного здоровью (вместо средней тяжести указывается тяжкий или наоборот)», что явно лежат вне пределов экспертной компетенции, и приводят к грубым экспертным ошибкам, когда эксперт подменяет следователя или суд.

\footnotetext{
${ }^{1}$ Предупреждение экспертных ошибок.- М., 1990.

${ }^{2}$ Комментарий к Уголовному кодексы РФ (постатейный). 2-е издание, исправленное, переработанное и дополненное /под ред. А.И. Чучаева. - М., 2010.
}

Далее авторы этого комментария высказывают весьма спорное суждение, что «в отличие от ложных показаний свидетеля, потерпевшего и специалиста умолчание экспертом о существенных обстоятельствах, выразившихся в том, что в заключении не была отражена часть фактов либо отсутствует их оценка, также образует состав рассматриваемого преступления». Опятьтаки неясно, почему не отражение каких-то фактов или отсутствие их оценки не результат экспертной ошибки или внутреннего убеждения эксперта в том, что эти обстоятельства не имеют значения при формулировании выводов, но обязательно сделано намеренно?

Полагаем, заведомо ложное заключение это умышленное действие, направленное на сознательное и целенаправленное игнорирование или умалчивание при исследовании существенных фактов и свойств объекта экспертизы. Оно может состоять в осознанных неверных действиях по проведению экспертизы, умышленно неверном применении или выборе методики экспертного исследования, заведомо неправильной их оценке. Осознание ложности своих выводов или неправильности действий исключают добросовестное заблуждение, как такое психологическое состояние, при котором субъект не осознает неправильности своих суждений или действий, а искренне полагает, что он мыслит и действует правильно.

В целом аналогично определяют ложное заключение эксперта комментарии к УК РФ под редакцией В. М. Лебедева («Заведомо ложное заключение эксперта - это преднамеренно неверный, не соответствующий действительности вывод по результатам исследования материалов, относящихся к предмету экспертизы»³) и под редакцией А. В. Бриллиантова («Ложность заключения эксперта выражается в намеренном искажении выявленных им фактов или в умолчании о них либо в неверной оценке фактов, ложных выводах из представленных для исследования материалов дела» ${ }^{4}$.

По своей природе экспертные ошибки неоднородны и могут быть разделены на три класса5: - ошибки процессуального характера;

\footnotetext{
${ }^{3}$ Комментарий к Уголовному кодексу Российской Федерации» (постатейный) 7-е издание, переработанное и дополненное / Отв. ред. В. М. Лебедев.- М., 2007.

${ }^{4}$ Комментарий к Уголовному кодексу Российской Федерации (постатейный) / Под ред. А. В. Бриллиантова.M., 2010.

${ }^{5}$ Белкин Р. С. Курс криминалистики.- М., 2001, с. 471.
} 
- гносеологические ошибки;

- д деятельностные (операционные) ошибки.

Экспертные ошибки проиессуального характера заключаются в нарушении экспертом процессуального режима и процедуры производства экспертизы:

- $\quad$ выход эксперта за пределы своей компетенции;

- $\quad$ выражение экспертной инициативы в непредусмотренных законом формах;

- обоснование выводов материалами дела, а не результатами исследования;

- самостоятельное собирание материалов и объектов экспертизы;

- осуществление несанкционированных судом (следователем) контактов с заинтересованными лицами, принятие поручения на производство экспертизы и материалов от неуполномоченных лиц;

- $\quad$ несоблюдение по незнанию процессуальных требований к заключению эксперта (в том числе отсутствие в заключении необходимых по закону реквизитов;

- обоснование выводов не результатами исследования, а материалами дела и др.).

Следует подчеркнуть, что процессуальные экспертные ошибки часто становятся следствием следственных и судебных ошибок, связанных с назначением судебной экспертизы и оценкой ее результатов. Например, при производстве судебной пожарно-технической экспертизы для установления механизма возникновения и развития пожара была назначена пожарно-техническая экспертиза. Государственный судебный эксперт получил непосредственно от ответчика аппарат электрозащиты, якобы с места пожара, произвел его исследование и дал категорический вывод в пользу ответчика, что аппарат защиты был исправен и не мог послужить причиной возникновения горения. Однако специалист, осмотревший аппарат защиты в ходе судебного заседания, указал на признаки, свидетельствующие о том, что аппарат защиты является новым и не мог находиться на месте пожара.

Здесь налицо, прежде всего, ошибка суда при назначении экспертизы, заключающаяся в нарушении нормы ч. 2 ст. 86 ГПК РФ: «Эксперт не вправе ... вступать в личные контакты с участниками процесса, если это ставит под сомнение его незаинтересованность в исходе дела...». Ошибка способствовала экспертной ошибке или даже заведомой ложности экспертного заключения, но в данном случае доказать заведомую ложность не представилось возможным.
Выход эксперта за пределы своей компетенции может заключаться в решении им вопросов, являющихся прерогативой правоприменителя, или вопросов, для ответов на которые вообще не требуется специальных знаний. Включение подобных вопросов в постановление (определение) о назначении судебной экспертизы - один из видов следственных (судебных) ошибок. Но если эксперт отвечает на подобный вопрос, а не отказывается от его решения - это уже экспертная ошибка. Постановка подобных вопросов эксперту не должна допускаться ${ }^{1}$, хотя это достаточно распространенное явление.

Например, по уголовному делу о мошенничестве была назначена судебно-бухгалтерская экспертиза, на разрешение которой вынесены вопросы:

1. Какое количество нефти в период февраль - май 2004 г. получило ООО «Х», от ОАO «Y»?

2. Кому, когда и как указанная нефть, полученная ООО «Х» была реализована?

3. Какими документами подтверждается получение нефти в период февраль май 2004 г. ООО «Х», от ОАО «Ү» (договора, акты приема - передачи нефти)?

4. Как и кем произведена оплата за нефть?

5. Причинен ли материальный ущерб ОАО «Ү», в каком размере?

Эксперт негосударственного судебно-экспертного учреждения дал ответы на все эти вопросы, тогда как совершенно очевидно, что первые четыре вопроса не относятся к предмету судебно-бухгалтерской экспертизы, да и вообще не требуют для своего решения проведения исследования с применением специальных знаний, которое является необходимым атрибутом судебной экспертизы. Все интересующие следователя данные либо содержатся в материалах дела, либо могут быть получены путем производства запросов в соответствующие организации. Неправомерность постановки пятого вопроса очевидна, поскольку вопрос о величине ущерба требует оценки всех имеющихся по делу доказательств, и, следовательно, его решение является прерогативой следствия и суда.

Одной из самых распространенных экспертных ошибок является самостоятельный сбор экспертом объектов для исследования. Согласно

\footnotetext{
${ }^{1}$ Постановления Пленума Верховного Суда Российской Федерации № 28 от 21 декабря 2010 г. «О судебной экспертизе по уголовным делам».
} 
процессуальному законодательству и ст. 17 Ф3 ГСЭД эксперт вправе знакомиться с материалами дела, но это право ограничено предметом экспертизы. К сожалению, на практике такие ошибки допускаются достаточно часто. Поясним это на примере.

По гражданскому делу для производства судебно-бухгалтерской экспертизы в распоряжение экспертов предоставлялся системный блок персонального компьютера из бухгалтерии ООО «L». Эксперт в своем заключении указывает, что выводы делались на основании «анализа данных $1 \mathrm{C}$-бухгалтерии (программы, посредством которой вели бухгалтерский учет в организации)». В данном случае исследование программного обеспечения и баз данных не относится к предмету судебно-бухгалтерской экспертизы, т.е. имеет место выход эксперта за пределы его компетенции, заключающийся в разрешении вопросов, относящихся к родам или видам экспертиз за пределами его экспертной специализации. Здесь сначала должна была быть назначена судебная компьютерно-техническая экспертиза: программно-компьютерная - для установления, какое программное обеспечение имеется на данном компьютерном устройстве и работает ли оно в штатном режиме; информационно-компьютерная экспертиза (данных), в ходе которой можно было бы установить, какие базы данных имеются на жестком диске системного блока ${ }^{1}$.

В определении суда о назначении судебнобухгалтерской экспертизы и предоставленных в распоряжение экспертов материалах даже не упоминалось, какого рода программное обеспечение было в системном блоке, функционировало ли оно в штатном режиме. Из заключения следовало, что эксперты-бухгалтеры сами обнаружили данное программное обеспечение и проанализировали его работу. При этом были выявлены базы данных, содержащие ряд документов бухгалтерской отчетности. Фактически, анализируя содержание жесткого диска системного блока, эксперты собирали доказательства и выбирали, что им исследовать и, тем самым, подменяли субъекта, назначившего экспертизу.

Самостоятельным сбором материалов для экспертизы является и анализ экспертом всех материалов дела. Эксперт вправе знакомиться с материалами дела, относящимися к предмету экспертизы. Но эти материалы должны

\footnotetext{
${ }^{1}$ Россинская Е.Р., Усов А.И. Судебная компьютерно-техническая экспертиза. - М.: Право и закон, 2001.
}

быть отобраны следователем, судом, органом, рассматривающим дело об административном правонарушении. В случае, когда представленных материалов недостаточно, эксперт имеет право запросить недостающие. Но право эксперта знакомиться с материалами дела ограничено предметом экспертизы. Эксперт не имеет права подменять субъектов, назначивших экспертизу, и заниматься анализом материалов дела, собирая доказательства, выбирая, что ему исследовать, например, анализировать, свидетельские показания, иначе могут возникнуть сомнения в объективности и обоснованности заключения.

В то же время, эксперт на практике фактически занимается собиранием вещественных доказательств в ходе экспертного исследования. Речь идет о ситуации с исследованием микроколичеств веществ и материалов, называемых в криминалистике микрообъектами. По существующей практике субъект, назначающий экспертизу, например, для установления факта контактного взаимодействия, обоснованно предполагая, что на тех или иных предметах имеются микрообъекты, прежде всего, задает вопрос: имеются ли на представленных для исследования предметах волокна, микрочастицы лакокрасочного покрытия, металла и пр. Аналогичные вопросы задаются иногда при необходимости обнаружения невидимых следов рук на изъятых предметах. Эксперт в ходе экспертного осмотра представленных предметов и при обнаружении микрообъектов (следов) фиксирует этот факт в своем заключении. Обнаруженные микрообъекты, приобретающие значение вещественных доказательств, подвергаются дальнейшему экспертному исследованию для решения других вопросов экспертного задания. Таким образом, эксперт фактически собирает (обнаруживает, фиксирует, изымает) доказательства, на что у него нет права согласно букве закона. К подобным действиям эксперта, явно выходящим за пределы его компетенции, следователь и суд относятся весьма снисходительно.

По мнению Л. В. Виницкого, осмотр предметов - вероятных носителей микрообъектов должен производиться по месту их обнаружения, как правило, при осмотре, с участием специалиста. Именно следователь составляет протокол об их обнаружении, в котором фиксируются их индивидуализирующие признаки ${ }^{2}$. Предло-

\footnotetext{
${ }^{2}$ Виницкий Л. В. Мельник С. П. Экспертная инициатива в уголовном судопроизводстве.- М., 2009.
} 
женное Л.В. Виницким решение действительно соответствует действующему законодательству и исключает его нарушение, но с точки зрения практики оно весьма трудно реализуемо. Вопервых, обнаружение микрообъектов в лабораторных условиях намного результативнее. Во-вторых, это процесс длительный, он может продолжаться несколько дней кряду, поэтому нереально постоянное присутствие следователя или судьи.

На основании вышеизложенного полагаем, что эксперту должно предоставляться право собирать доказательства при исследовании предметов - возможных носителей микрообъектов - и при производстве некоторых видов экспертиз. Кстати законодатель уже сделал шаг на этом пути, установив в ч.4 ст. 202 УПК РФ, что если получение образцов для сравнительного исследования является частью судебной экспертизы, то оно производится экспертом.

Другой характерной экспертной ошибкой, а именно вариантом экспертной инициативы в непредусмотренной законом форме, является изменение экспертом формулировки вопроса, поставленного на его разрешение. К сожалению, зачастую формулировки вопросов не соответствует общепринятым рекомендациям. Ни в одном процессуальном кодексе, равно, как и в ФЗ ГСЭД, судебному эксперту не предоставляется право переформулировать вопросы. Он может только обратиться к следователю или суду с ходатайством о предоставлении дополнительных материалов. Но можно ли считать уточнение вопросов предоставлением дополнительных материалов, ведь вопросы уже зафиксированы в постановлении (определении) - процессуальном документе, принятом в соответствии с определенной процессуальной процедурой?

На практике такая проблема возникает ежедневно по всем категориям дел. Например, при рассмотрении в арбитражном суде дела, связанного с пожаром на промышленном объекте, перед экспертом был поставлен вопрос: «Как соотносится с пожаром оплавление медной проводки?» В соответствии с методикой исследования металлических проводников в зонах короткого замыкания и термического воздействия ${ }^{1}$, эксперт переформулировал вопрос и дал его в следующей редакции: «Какова природа оплавления медных

\footnotetext{
${ }^{1}$ Исследование медных и алюминиевых проводников в зонах короткого замыкания и термического воздействия.—- М.: ВНИИ МВД СССР, 1986.
}

проводников? Если оплавление вызвано коротким замыканием, то произошло ли оно до начала пожара или в процессе его развития?». Ясно, что последние два вопроса сформулированы корректнее и позволяют эксперту дать категорические выводы, имеющие большое доказательственное значение. Но с формальной точки зрения эксперт вышел за пределы своей компетенции.

В п.30 Инструкции по организации производства судебных экспертиз в ЭКП ОВД Российской Федерации, утвержденной приказом МВД России № 511 от 29 июня 2005 г. указывается, что «в случае необходимости эксперт имеет право изменить редакцию вопросов, не изменяя их смысл».

Таким образом, МВД своим приказом наделил экспертов органов внутренних дел правом изменять формулировки вопросов, выносимых на разрешение эксперта. Как нам представляется, это достаточно вольная трактовка права эксперта выйти за пределы экспертного задания и ответить на вопросы, которые не были поставлены, предусмотренного ст. 86 ГПК, ст. 86 АПК, 204 УПК, ст. 25.9 КоАП. Анализ судебной практики показывает, что во многих случаях, особенно в гражданском и арбитражном процессе, такие заключения оспариваются именно по формальным признакам. Стороны или их представители обжалуют изменение формулировок вопросов без их участия и указывают на нарушение своих прав при назначении экспертизы.

Представляется, что судебного эксперта необходимо наделить правом переформулировать вопросы, вынесенные на его разрешение, если они сформулированы некорректно с точки зрения теории и методики судебной экспертизы и уведомить об этом в определенный срок субъекта, назначившего экспертизу. Однако пока законодательно это право эксперта не закреплено, порядок может быть только один. Если эксперт является сотрудником судебно-экспертного учреждения, то необходимость изменения формулировки вопросов он согласует с руководителем учреждения, который, в свою очередь, извещает об этом субъекта, назначившего экспертизу. Далее следователем вносятся изменения в постановление о назначении экспертизы или суд выносит новое определение. Частный эксперт обращается с этим вопросом непосредственно к субъекту, назначившему экспертизу.

Весьма распространенной ошибкой процессуального характера является несоблюдение по незнанию процессуальных требований к заклю- 
чению эксперта (в том числе отсутствие в заключении необходимых по закону реквизитов ${ }^{1}$.

В государственных судебно-экспертных учреждениях, где экспертная деятельность является основной, требования к форме экспертного заключения, как правило, соблюдаются. Большинство ошибок процессуального характера, связанных с неправильным оформление заключений судебной экспертизы, допускают частные эксперты, не являющиеся сотрудниками экспертных учреждений. Хотя в экспертизах, выполненных в негосударственных судебно-экспертных учреждениях, такие ошибки также встречаются.

Типичными ошибками процессуального характера такого рода являются:

- $\quad$ нарушение процедуры предупреждения эксперта об уголовной ответственности за дачу заведомо ложного заключения;

- отсутствие сведений об экспертах, производивших экспертизу: их образовании; экспертной специальности, стаже экспертной работы и пр.;

- отсутствие исследовательской части заключения как таковой;

- отсутствие в заключении подробного описания объектов, представленных на экспертизу;

- $\quad$ отсутствие подробного описания технологии экспертного исследования, включающей рекомендованную (сертифицированную) экспертную методику, а если таковой не имеется ссылок на научную литературу, содержащую рекомендации по исследованию подобных объектов;

- отсутствие описания осуществленных экспертных экспериментов и условий их проведения;

- отсутствие синтезирующей части в заключениях комиссионных и комплексных экспертиз;

- отсутствие выводов эксперта и их собственноручных подписей;

- подписание экспертом частей заключения, которые выполнены без его участия другими экспертами и другие.

Ошибки могут быть связаны с неправильной трактовкой, как субъектами правоприменения, так и руководителями организаций, понятия негосударственное судебно-экспертное учреждение. Зачастую по ним понимается любая организация,

\footnotetext{
${ }^{1}$ Ст. 25 ФЗ ГСЭД, ст. 86 АПК, ст. 204 УПК, ст. 86 ГПК, п. 5 ст. 26.4 КоАП
}

где работают лица, обладающие необходимыми специальными знаниями. Однако Пленум Верховного Суда разъяснил, что под негосударственными судебно-экспертными учреждениями следует понимать некоммерческие организации (некоммерческие партнерства, частные учреждения или автономные некоммерческие организации), созданные в соответствии с Гражданским кодексом Российской Федерации и Федеральным законом "О некоммерческих организациях", осуществляющие судебно-экспертную деятельность в соответствии с принятыми ими уставами ${ }^{2}$.

Переложение судом своих функций по выбору персоны негосударственного эксперта, проверке его компетенции, разъяснению ему процессуальных прав и ответственности на руководителя неэкспертного учреждения недопустимо. Но во многих случаях НИИ, вузы и другие организации, не являющиеся судебно-экспертными учреждениями, принимают к исполнению постановления и определения, вынесенные следователями и судами, их руководители позиционируют себя как руководители судебно-экспертных учреждений, фактически таковыми не являясь, не имея ни полномочий, ни соответствующих навыков и знаний. Верховный Суд, рассмотрев эту проблему, разъяснил, что во избежание следственных, судебных и экспертных ошибок суд также вправе поручить проведение судебной экспертизы не государственной организации, а «... сотруднику научно-исследовательского учреждения, вуза, иной организации, обладающему специальными знаниями и имеющему в распоряжении необходимое экспертное оборудование. Поэтому назначать можно только не НИИ, вузу как юр. Лицу, а конкретным сотрудникам, работающим в этих учреждениях» ${ }^{3}$.

Процессуальным нарушением является также отсутствие во водной части заключения сведений об эксперте. Более того в ряде случаев эти сведения, затребованные при назначении экспертизы согласно Постановлениям Верховного Суда РФ и Высшего Арбитражного Суда РФ ${ }^{4}$, содержат

\footnotetext{
${ }^{2}$ П.2 Постановления Пленума Верховного Суда Российской Федерации № 28 от 21 декабря 2010 г. «О судебной экспертизе по уголовным делам».

${ }^{3}$ Там же п. 5.

${ }^{4}$ П. 3 Постановления Пленума Верховного Суда Российской Федерации № 28 от 21 декабря 2010 г. «О судебной экспертизе по уголовным делам»; п.1 Постановления Пленума Высшего Арбитражного Суда Российской Федерации № 23 от 4 апреля 2014 г. «О некоторых вопросах практики применения арбитражными судами законодательства об экспертизе».
} 
искаженную информацию о компетентности эксперта. Речь идет, в первую очередь, о смешении понятий «стаж работы по специальности» и «стаж экспертной работы», которые не всегда совпадают.

Проиллюстрируем это на примере. Эксперт окончил Институт судебных экспертиз Московского государственного юридического университета имени О. Е. Кутафина (МГЮА) по специальности «судебная экспертиза» со специализацией «судебные экономические экспертизы», но начал производить почерковедческие экспертизы, не пройдя обучения и не обладая необходимой квалификацией.

Заключения многих негосударственных экспертов, как уже указывалось выше, выполнены как отчеты о проделанной работе, часто не содержат исследовательской и синтезирующей части ссылок на методики исследования. Более того, нередки случаи, когда руководитель организации неэкспертной организации сам утверждает заключение и подписывает его вместо экспертов.

Остановимся далее на экспертных ошибках процессуального характера, связанных с производством комплексных экспертиз.

По одному уголовному или гражданскому делу можно производить комплекс различных cyдебных экспертиз, как в отношении одного и того же объекта, так и группы объектов. Однако нередко такие экспертизы назначаются как комплексные. Например, по документу, содержащему рукописный текст подпись и печать, была назначена комплексная дактилоскопическая, почерковедческая и судебно-техническая экспертиза документов, хотя должен был быть назначен комплекс судебных экспертиз: судебная дактилоскопическая; судебная почерковедческая рукописного текста; судебно-техническая экспертиза документов.

Ошибочно рассматривать и оформлять данные исследования как комплексную экспертизу. Следственная ошибка назначения такой экспертизы как комплексной нередко приводит к процессуальной экспертной ошибке, когда эксперты производившие никак не связанные между собой исследования, подписывают общий вывод.

В рамках экспертизы одного рода (вида) может выполняться комплексное исследование одних и тех же вещественных доказательств с использованием различных методов, однако такое исследование не является комплексной экспертизой, даже если оно выполнено комиссией экспертов.
Например, по делу о пожаре изъяты провода. Решение вопроса о том, произошли ли их оплавления в результате коротких замыканий (до или во время пожара) или термического действия пожара, осуществляется с использованием таких современных инструментальных методов, как растровая электронная микроскопия, рентгеноструктурный, металлографический и газовый анализ ${ }^{1}$. Исследование может производиться как одним экспертом-металловедом, владеющим этими методами, так и разными экспертами, каждый из которых специализируется в каком-то одном методе, но все они, являясь специалистами в области металловедческих экспертиз, владеют и другими методами исследования.

Несмотря на то, что в постановлениях о назначении подобных экспертиз часто фигурирует термин «комплексные», они таковыми не являются и представляют собой экспертизы с использованием комплекса методов в пределах одного и того же вида судебной экспертизы. Это утверждение коррелирует с классификаторами судебных экспертиз, утвержденными приказами различных ведомств для проведения аттестаций государственных судебных экспертов, поскольку в соответствии с судебной экспертологией современные классификации судебных экспертиз осуществляются не по методам экспертных исследований, которые во многом являются общими для разных родов экспертиз, а по исследуемым объектам в совокупности с решаемыми задачами ${ }^{2}$.

Комплексной является такая экспертиза, при производстве которой решение вопроса невозможно без одновременного совместного участия экспертов различных родов (видов) судебных экспертиз в написании заключения (или его синтезирующей части) и формулирования общего вывода. Очевидно, что при этом каждый эксперт обладает не только узкой специализацией, но и знаниями в пограничных областях наук, которые использованы при даче заключения ${ }^{3}$.

Иной позиции придерживаются некоторые ученые-процессуалисты. Так профессор Ю. К. Орлов полагает, что «комплексная экспер-

\footnotetext{
${ }^{1}$ Россинская Е.Р. Рентгеноструктурный анализ в криминалистике и судебной экспертизе. Киев, 1992.

${ }^{2}$ Россинская Е. Р. Современные представления о предмете и системе судебной экспертологии //Lex Russica, № 4, 2013, c.421-428.

3. Россинская Е.Р. Комплексные судебные экспертизы: гносеологическая и процессуальная составляющие // Судебная экспертиза, № 3, 2012.
} 
тиза является разновидностью комиссионной ${ }^{1}$. Он справедливо указывает, что признаками комплексной экспертизы является участие в ее производстве экспертов разных специальностей и дача ими совместного заключения на основе не только лично проведенных исследований, но и по результатам исследований, проведенных другими экспертами. Но далее Ю. К. Орлов указывает, что «в составлении синтезирующей части и формулировании общих выводов могут принимать участие не все эксперты, а только эксперты иирокого профиля, компетентные в общем предмете исследования. Эксперты узкого профиля, не компетентные в этом предмете, после формулирования ими промежуточных выводов в дальнейшем исследовании не участвуют». Что имеется в виду под широким профилем нам неясно. Скорее всего, речь идет о разных экспертных специализациях. Мы совершенно согласны с Ю.Г. Коруховым, что формулировать вывод может наиболее опытный эксперт, а остальные лишь участвуют в этом ${ }^{2}$. Действительно, при производстве сложных комплексных экспертиз на практике текст синтезирующей части пишет, сначала кто-то один, как правило, самый опытный эксперт, обладающий разносторонними знаниями. Но это не значит, что другие эксперты не принимают участия в подготовке текста заключения и формулировании выводов.

Серьезной экспертной ошибкой является интерпретация и разъяснения одним экспертов результатов исследования другого в одном и том же заключении, если, как пишет, например, Ю. К. Орлов, вывод эксперта понятен только другому эксперту. На практике бывают случаи, когда легковесные, не подкрепленные исследованиями выводы даются в псевдонаучной форме, затрудняющей понимание или попросту делающим его невозможным.

Гносеологические ошибки коренятся в сложностях процесса экспертного познания. Они могут быть допущены при познании сущности, свойств, признаков объектов экспертизы, отношений между ними, а также при оценке результатов

\footnotetext{
${ }^{1}$ Орлов Ю.К. Комплексная экспертиза, комплексное исследование и комплекс экспертиз: соотношение понятий // Материалы 2-й Международной научно-практической конференции «Теория и практика судебной экспертизы в современных условиях» (г. Москва, 24-25 июня 2009 г.). M., 2009

${ }^{2}$ Корухов Ю.Г. Проблема комплексности в судебной экспертизе. (К вопросу о законодательной регламентации) // Теория и практика судебной экспертизы, № 3 (15), 2009.
}

познания, итогов экспертного исследования, их интерпретации. Они делятся на логические и фактические (предметные) $)^{3}$.

Логические ошибки связаны с нарушением в акте мышления законов и правил логики, некорректным применением логических приемов и операций, например смешение причинной связи с простой последовательность во времени или обоснование тезиса аргументами, из которых данный тезис логически не вытекает. Такие ошибки обычно связаны с различными логическими операциями и видами умозаключений. Так, можно выделить ошибки в делении понятий, в определении понятий, ошибки в индуктивном выводе, ошибки в дедуктивных умозаключениях, ошибки в доказательстве: по отношению к тезису, к аргументу, к демонстрации ${ }^{4}$.

В экспертных заключениях распространены и другие формально-логические ошибки, как например: вывод не является логическим следствием осуществленного экспертом исследования; отсутствует логическая обусловленность последовательности стадий экспертного исследования; по одному и тому же предмету даны противоречивые выводы экспертов; выводы эксперта недостаточно мотивированы ${ }^{5}$.

Распространенными логическими ошибками являются несоответствия выводов и исследовательской части заключения. Например, исследовательская часть формулируется в вероятной форме, а выводы - в категорической, что из исследования не вытекает или ответ на вопрос приведен только в выводах, а в исследовательской части обоснование этого ответа вообще отсутствует.

Фактические (предметные) ошибки проистекают от искаженного представления об отношениях между предметами объективной действительности. Следует подчеркнуть, что предметные ошибки, которые относятся к содержанию экспертного умозаключения, могут быть замечены и исправлены только тем, кто знаком с самим предметом, о котором идет речь. На практике имеют место случаи использования для обоснования экспертного вывода выявленных при исследовании одного объекта-носителя

\footnotetext{
${ }^{3}$ Белкин Р.С. Криминалистика: проблемы сегодняшнего дня.- М., 2001, с. 188.

${ }^{4}$ Ивин А.А., Никифоров А. Л. Словарь по логике.- М., 1997. C. 261

${ }^{5}$ Россинская Е.Р. Галяшина Е.И. Настольная книга судьи. Судебная экспертиза.- М., 2013.
} 
экспертами разных специальностей (или одним экспертом, владеющим специальными знаниями из разных специальностей) признаков, которые не могут образовывать совокупность, но должны анализироваться отдельно для каждого вида (рода) экспертиз.

Поясним это на примере. При идентификационном исследовании окурка со следами зубов и пальцев рук экспертом трасологом, даже если он имеет право выполнять судебные дактилоскопические экспертизы и судебные трасологические экспертизы следов зубов, идентификационные признаки зубов в следах, которых недостаточно для категорического вывода об индивидуальном тождестве не могут быть дополнены признаками папиллярных узоров, также не образующих совокупность, необходимую для индивидуальной идентификации. Объектами исследования в данном случае будет не окурок, но следы.

Деятельностные (операционные) ошибки связаны с осуществляемыми экспертом операциями (процедурами) и могут заключаться в: а) нарушении предписанной последовательности этих процедур; б) неправильном использовании средств исследования или использовании непригодных средств, например использование аппаратуры, давно не проходившей поверку; в) получении некачественного сравнительного материала и т.п. В многих случаях фактические ошибки сопровождаются деятельностными, и наоборот деятельностные - фактическими, поскольку и те и другие связаны с профессиональной компетенцией эксперта и могут быть выявлены, как правило только лицами, обладающими соответствующими специальными знаниями. Поэтому целесообразно рассматривать эти ошибки в комплексе по стадиям экспертного исследования.

Наиболее распространенные ошибки на подготовительной стадии экспертного исследования: непригодность объектов для исследования; неверное представление об объектах исследования; недостаточное количество или низкое качество сравнительных образцов; ошибочные экспертные версии, которые впоследствии не были уточнены; выбор методов или методик исследования, не соответствующих объектам.

На аналитической стадии экспертного исследования в процессе раздельного исследования экспертные ошибки связаны как с выбором инструментария, так и с особенностями его применения. Использование без какой-либо модификации и критического переосмысления для исследования вещественных доказательств методик, разработанных в «большой науке», нередко приводит к экспертным ошибкам. Наиболее типичной такой ошибкой является отсутствие четких представлений о микрообъектах, их природе и связи с макрообъектами. Экспертные ошибки на этапе индивидуализации каждого объекта в отдельности связаны с выявлением и анализом общих (групповых) и частных признаков.

На стадии сравнительного исследования ошибки допускаются при выявлении совпадений или различий признаков сравниваемых объектов между собой, со сравнительными образцами или эталонами, сопоставлении выявленных идентификационных признаков, присущих каждому объекту, и установлении совпадающих и различающихся.

Например, точечный след сравнивается с линейным, прямое отображение с зеркальным и т.д. Ошибкой является и завершение исследование констатацией совпадений или различий, отсутствие в экспертном заключении описания стадии оценки признаков, на которой происходит суммирование результатов исследования, подведение его итогов и формулирование выводов.

При проведении экспертного эксперимента допускаются ошибки в воспроизведении признаков проверяемого объекта, неверно толкуется механизм следового взаимодействия и его возможности в конкретных условиях (ситуациях), неверно выбираются методы исследования, последовательности действий, т. е. с экспертные технологии.

На завершающей стадии экспертного исследования при формулировании выводов, помимо логических ошибок, о которых упоминалось выше, могут быть допущены фактические и операционные ошибки. К таким ошибкам относится отсутствие синтезирующей части в заключении комиссионной или комплексной экспертизы. При производстве комплексных экспертиз неверная интерпретация одними членами комиссии экспертов признаков или промежуточных выводов, выявленных другими экспертами. Нередко эксперты смешивают категорический вывод о родовой (групповой) принадлежности с вероятным выводом. Более того, вывод в вероятной форме дается чисто умозрительно, без всякого обоснования, хотя также как и при категорическом суждении, такой вывод должен основываться на достаточной совокупности достоверно установленных промежуточных данных и высокой степени вероятности их существования. В противном 
случае следует отказаться от решения вопроса. Хотя использование таких выводов правоприменителем и ограниченно, но они не должны быть голословными, поскольку могут оказать помощь при выдвижении и проверке версий, установлении существования фактов и пр.

Причины экспертных ошибок могут быть объективными и субъективныли. К ним экспертным ошибкам объективной природы относятся:

- несовершенство используемой экспертной методики или ее отсутствие;

- применение ошибочно рекомендованных методов, методов и приборов, не обладающих достаточной чувствительностью или разрешающей способностью, применение неисправного или не сертифицированного оборудования;

- использование неадекватных математических моделей и компьютерных программ, нелицензионного программного обеспечения и др. ${ }^{1}$

К субъективным причинам экспертных ошибок относится, прежде всего, профессиональная некомпетентность эксперта: незнание современных экспертных методик, неумение применять современные экспертные технологии, отсутствие навыков работы с аппаратурой, техническими средствами, компьютерными средствами и системами, неправильная оценка идентификационной значимости признаков и т.д. Субъективными ошибками являются также неполнота исследования, его односторонность.

Субъективными ошибками являются и профессиональные упущения эксперта: небрежность, неаккуратность, невнимательность, поверхностное производство исследования. Подобные ошибки могут быть связаны с определенными чертами личности эксперта, как-то: дефекты или недостаточная острота органов чувств эксперта; болезнь, переутомление, стресс, эмоциональное или психическое напряжение, поспешности; неуверенность в своих знаниях; повышенная внушаемость; мнительность; конформизм, или наоборот излишняя самоуверенность, амбициозность, пренебрежение мнением коллег и др. ${ }^{2}$

Экспертные ошибки могут быть обнаружены:

\footnotetext{
${ }^{1}$ Россинская Е.Р. Галяшина Е.И. Настольная книга судьи: Судебная экспертиза.- М., 2013.

2 Подробнее об этом см. Россинская Е. Р., Галяшина Е.И., Зинин А. М. Теория судебной экспертизы. Учебник для вузов. /Под ред. Е.Р. Россинской. М., 2013.
}

- $\quad$ при проверке самим экспертом хода и результатов проведенного им исследования на любой его стадии, и особенно на стадии формирования вывода.

- $\quad$ при анализе и обсуждении результатов экспертного исследования, осуществляемого комиссией экспертов при производстве однородной комиссионной и комплексной экспертизы;

- $\quad$ при анализе экспертом или специалистом заключений предшествующих экспертиз;

- $\quad$ при контроле хода и результатов экспертного исследования руководителем экспертного учреждения;

- следователем, присутствующим при производстве экспертизы;

- $\quad$ при оценке заключения эксперта следователем или судом (первой, апелляционной, кассационной; надзорной инстанций).

- в вроцессе обобщения экспертной практики, осуществляемом в практических или научных целях.

Существенное для судопроизводства значение имеет обнаружение тех ошибок, которые повлекли или могли повлечь неправильный вывод эксперта. При обнаружении таких ошибок эксперт или руководитель экспертного учреждения обязан поставить в известность орган, назначивший экспертизу. Если эксперт (эксперты) обнаруживает ошибку в заключении предшествующей экспертизы, то он принимает меры к недопущению подобной ошибки в своем исследовании и учитывает ее при объяснении различий между своими и предыдущими выводами. Если ошибка замечена следователем, присутствующим при производстве экспертизы, то он немедленно ставит об этом в известность эксперта. Однако на практике подобная ситуация практически не встречается.

Значительно чаще экспертные ошибки обнаруживаются при оценке экспертных заключений судом (следователем). Если ошибка не влияет на выводы эксперта, она может быть нейтрализована или устранена путем его допроса или назначения дополнительной экспертизы. В противном случае может быть назначена повторная экспертиза.

Следует подчеркнуть, что наиболее сложно для правоприменителя, необладающего соответствующими специальными знаниями, выявить гносеологические и деятельностные экспертные ошибки. Поэтому в соответствии с ч.2 п. 19 Постановления Пленума Верховного Суда РФ и п. 7 Постановления Пленума Высшего Арбитражного 
Суда РФ для оказания помощи в оценке заключения эксперта может привлекаться специалист ${ }^{1}$. Специалист может дать разъяснения о пригодности и достаточность объектов и образцов для сравнительного исследования с точки зрения используемых экспертных методик; о методиках, использованных при производстве судебной экспертизы их научной обоснованности граничных условиях применения, допустимость использования избранной методики в данном конкретном случае; об обоснованности выводов эксперта, взаимосвязи и взаимообусловленности выводов и исследовательской части экспертного заключения и пр.
Причина ошибочности экспертного заключения может быть не только в допущенных экспертом ошибках. Экспертное исследование может быть выполнено безупречно, сделанные выводы полностью соответствуют полученным результатам. Но если исходные данные были ошибочными или исследуемые объекты не имели отношения к делу, были фальсифицированы, то и заключение эксперта в аспекте установления истины по делу окажется ошибочным. Однако в этом случае нельзя говорить об экспертной ошибке, поскольку причиной ошибочного заключения является ошибка субъекта, назначившего экспертизу, либо его умышленно неправильные действия, правонарушения.

\section{Библиография}

1. Белкин Р. С. Криминалистика: проблемы сегодняшнего дня.- М., 2001.

2. Белкин Р.С. Курс криминалистики.- М., 2001.

3. Виницкий Л. В., Мельник С. П. Экспертная инициатива в уголовном судопроизводстве. - М., 2009.

4. Ивин А. А., Никифоров А. Л. Словарь по логике.- М., 1997.

5. Исследование медных и алюминиевых проводников в зонах короткого замыкания и термического воздействия. - М.: ВНИИ МВД СССР, 1986.

6. Комментарий к Уголовному кодексу Российской Федерации (постатейный) / под ред. А.В.Бриллиантова.- М., 2010.

7. Комментарий к Уголовному кодексу Российской Федерации (постатейный) 7-е издание, переработанное и дополненное / Отв. ред. В. М. Лебедев. - М., 2007.

8. Комментарий к Уголовному кодексы РФ (постатейный). 2-е издание, исправленное, переработанное и дополненное / под ред. А. И. Чучаева.- М., 2010.

9. Корухов Ю.Г. Проблема комплексности в судебной экспертизе. (К вопросу о законодательной регламентации) //Теория и практика судебной экспертизы. - 2009. — № 3 (15).

10. Орлов Ю. К. Комплексная экспертиза, комплексное исследование и комплекс экспертиз: соотношение понятий // Материалы 2-й Международной научно-практической конференции «Теория и практика судебной экспертизы в современных условиях» (г. Москва, 24-25 июня 2009 г.). М., 2009.

11. Предупреждение экспертных ошибок.—М., 1990.

12. Россинская Е. Р. Галяшина Е. И. Настольная книга судьи. Судебная экспертиза. — М., 2013.

13. Россинская Е. Р. Комплексные судебные экспертизы: гносеологическая и процессуальная составляющие // Судебная экспертиза. — 2012.— № 3.

14. Россинская Е.Р. Рентгеноструктурный анализ в криминалистике и судебной экспертизе. Киев, 1992.

15. Россинская Е.Р. Современные представления о предмете и системе судебной экспертологии // Lex Russica. - 2013. - № 4.

16. Россинская Е. Р., Галяшина Е. И., Зинин А. М. Теория судебной экспертизы. Учебник для вузов. / под ред. Е. Р. Россинской.- М., 2013.

17. Россинская Е. Р., Усов А. И. Судебная компьютерно-техническая экспертиза. - M. - 2001.

\footnotetext{
${ }^{1}$ Постановление Пленума Верховного Суда Российской Федерации № 28 от 21 декабря 2010 г. «О судебной экспертизе по уголовным делам»; Постановление Пленума Высшего арбитражного Суда Российской Федерации № 23 от 4 апреля 2014 г. «О некоторых вопросах практики применения арбитражными судами законодательства об экспертизе».
} 


\section{References (transliterated)}

1. Belkin R. S. Kriminalistika: problemy segodnyashnego dnya.-M., 2001.

2. Belkin R. S. Kurs kriminalistiki.- M., 2001.

3. Vinitskii L. V., Mel'nik S. P. Ekspertnaya initsiativa v ugolovnom sudoproizvodstve. - M., 2009.

4. Ivin A. A., Nikiforov A. L. Slovar» po logike.— M., 1997.

5. Issledovanie mednykh i alyuminievykh provodnikov $\mathrm{v}$ zonakh korotkogo zamykaniya i termicheskogo vozdeistviya.-M.: VNII MVD SSSR, 1986.

6. Kommentarii k Ugolovnomu kodeksu Rossiiskoi Federatsii (postateinyi) / pod red. A. V. Brilliantova.M., 2010.

7. Kommentarii k Ugolovnomu kodeksu Rossiiskoi Federatsii (postateinyi) 7-e izdanie, pererabotannoe i dopolnennoe / Otv. red. V. M. Lebedev. - M., 2007.

8. Kommentarii k Ugolovnomu kodeksy RF (postateinyi). 2-e izdanie, ispravlennoe, pererabotannoe i dopolnennoe / pod red. A. I. Chuchaeva.- M., 2010.

9. Korukhov Yu.G. Problema kompleksnosti v sudebnoi ekspertize. (K voprosu o zakonodatel'noi reglamentatsii) //Teoriya i praktika sudebnoi ekspertizy. — 2009. - № 3 (15).

10. Orlov Yu.K. Kompleksnaya ekspertiza, kompleksnoe issledovanie i kompleks ekspertiz: sootnoshenie ponyatii // Materialy 2-oi Mezhdunarodnoi nauchno-prakticheskoi konferentsii «Teoriya i praktika sudebnoi ekspertizy v sovremennykh usloviyakh» (g. Moskva, 24-25 iyunya 2009 g.). M., 2009.

11. Preduprezhdenie ekspertnykh oshibok. - M., 1990.

12. Rossinskaya E. R. Galyashina E. I. Nastol'naya kniga sud'i. Sudebnaya ekspertiza. - M., 2013.

13. Rossinskaya E. R. Kompleksnye sudebnye ekspertizy: gnoseologicheskaya i protsessual'naya sostavlyayushchie // Sudebnaya ekspertiza. - 2012. - № 3 .

14. Rossinskaya E. R. Rentgenostrukturnyi analiz v kriminalistike i sudebnoi ekspertize. Kiev, 1992.

15. Rossinskaya E. R. Sovremennye predstavleniya o predmete i sisteme sudebnoi ekspertologii //Lex Russica. - 2013. - № 4 .

16. Rossinskaya E. R., Galyashina E. I., Zinin A. M. Teoriya sudebnoi ekspertizy. Uchebnik dlya vuzov. / pod red. E. R. Rossinskoi.- M., 2013.

17. Rossinskaya E. R., Usov A. I. Sudebnaya komp'yuterno-tekhnicheskaya ekspertiza. - M. - 2001. 